Original Research Article

\title{
Herbal products: utilization, knowledge and attitudes of Turkish adults
}

\author{
Gülay Yilmazel ${ }^{1 *}$, Melis Naçar $^{2}$
}

\author{
${ }^{1}$ Assistant Professor, \\ Department of Public Health, \\ School of Health, Hitit \\ University, Çorum, Turkey \\ ${ }^{2}$ Associate Professor, \\ Department of Medical \\ Education, Faculty of Medicine, \\ Erciyes University, Kayseri, \\ Turkey
}

Received: 10 August 2016 Accepted: 15 September 2016

\section{*Correspondence to: \\ Dr. Gulay Yilmazel, \\ Email: dryilmazelgul @ gmail.com}

Copyright: (C) the author(s), publisher and licensee Medip Academy. This is an openaccess article distributed under the terms of the Creative Commons Attribution NonCommercial License, which permits unrestricted noncommercial use, distribution, and reproduction in any medium, provided the original work is properly cited.

\section{ABSTRACT}

Background: This study was aimed to determine utilization, knowledge and attitudes of Turkish adults on herbal products.

Methods: This cross-sectional study was conducted in a Turkey city-Çorum with 600 adults aged between 18-85 during June 2015. A self-administered questionnaire was used to collect data on demographics, and general knowledge, experiences and attitudes about herbal products.

Results: Of these responses, $67.3 \%$ of were women and $32.7 \%$ were men; $34.7 \%$ were aged 35-49 years with the mean age of 33.7. The $14.2 \%$ had any chronic disease and of these $38.8 \%$ were suffering from cardiovascular disease and hypertension. The overall utilization of herbal products was 55.7\%. Most common health issues treated via HPs by respondents were found to be intestinal illness and losing weight. Responses had predominantly negative but sophisticated attitudes towards to herbal products. Women were more likely to be users with the increased risk of 1.9 times higher than men. Also family size, chronic conditon and current medication use were significant predictors of herbal produts use. Herbal product use was significantly higher in responses who had "moderate-bad" health perception. Among the attitudes, attitude -7 and attitude -11 were the other strongest factors on herbal product use.

Conclusions: The present study confirms previous findings and provides additional evidence that using herbal products among Turkish adults is still prevalent with the lack of information and semi-positive attitudes.

Keywords: Attitudes, Adults, Herbs, Self-administration, Utilization

\section{INTRODUCTION}

Herbal products (HPs) are defined as raw or processed active herbal ingredients made from one or more herbs. ${ }^{1}$ It is in widespread usage throughout the World. ${ }^{2}$ Prevalence and predictors of attitudes among population vary from country to country. ${ }^{3}$ World Health Organization (WHO) estimates that up to $80 \%$ of the population in developing countries use traditional herbal medicine for primary health care. ${ }^{4}$ The reason for the growing popularity of its that fully accepted by consumers as natural and reliable. HPs are an increasingly utilization as self-treatment prescription for maintaining good health and illness prevention among patients and general public. ${ }^{3-6}$ In today's world, higher prevalence of chronic disease pattern, obesity, common pain symptoms lead to increased use. ${ }^{7}$ International organizations have published guidelines for clinical trials of herbal products to evaluate the benefits and risks. ${ }^{1,2}$ Despite its natural origin, these products are chemically active substances including synthetic compounds and can be extremely harmful to human beings. One of the main obstacles, life threatening adverse effects such as intoxications, drug interactions, multiple organ failures and deaths. $1,3,6,8$

Previous studies have documented that there is increasing concern on HPs as an alternative to modern medicine in Turkish population. ${ }^{9-10}$ These products can choose a therapeutic option but only if use properly and under the 
guidance of a physician. This study was aimed to determine utilization, knowledge and attitudes of Turkish adults on herbal products.

\section{METHODS}

\section{Target population and sample}

This cross-sectional study was conducted in an Anatolian city-Çorum with adults aged between $18-85$ years in June 2015. Çorum is an inland from the middle black sea region in central Turkey and valuable for Hittite archaelogy. The target population consisted of 1423 adults who residing regional boundaries of a Family Health Center (FHC) and who were registered in a family physician records at this center (FHC). Of these, 1000 were reached during June and 600 were volunteer participating to study. Face to face interviews were conducted via self-administered questionnaire.

\section{Study design and analysis}

The questionnaire has been divided into two parts. The first part deals with demographic data of adults focusing on gender, age, educational level, marital status, type of family, occupation, location of residence, income level, chronic disease, continuous medication use, current perceived general health. Second part presents the respondent's general knowledge, experiences and attitudes about HPs following as -What comes to your mind when called HPs? , did you use HPs for selftreatment? If yes a) in which situations did you use it for self-treatment? b) How did you get a result after using HPs? (Answers as I recovered completely, I recovered partially, good for nothing, it was harmful).

In order to identify attitudes, the participants were asked to 13-item attitude questions with three likert scale (yes, no, undecided):

Table 1: Attitude questions related to herbal products.

\begin{tabular}{|ll|}
\hline \multicolumn{1}{|c|}{ Attitude questions } \\
\hline Attitude & 1: I think it's more effective than medicines. \\
\hline Attitude & 2: I think it's harmless. \\
\hline Attitude & 3: I think it's usage easier than medicines. \\
\hline Attitude & 4: I'm looking optimistically using HPs and pull out of medication that prescribed by physician. \\
\hline Attitude & 5: I find HPs advertisement believable in the media. \\
\hline Attitude & 6: I believe that those who marketing HPs pay regard public health. \\
\hline Attitude & 7: I think I should notify to doctor who regulate my medication when I use it for therapeutic purpose. \\
\hline Attitude & 8: I think consumption of high amounts of the HPs could be detrimental. \\
\hline Attitude & 9: I think, HPs could change the effect of drugs when used in conjunction with drugs. \\
\hline Attitude & 10: I think, some of the HPs might be killer. \\
\hline Attitude & 11: I never use herbal products for my child. \\
\hline Attitude & 12: Even though using medicine due to illness would you use along with HPs? \\
\hline Attitude & 13: If you hear one of damaged due to HPs do you give up using it? \\
\hline
\end{tabular}

\section{Statistical analysis}

In analysis, for categorical variables chi-squared test was conducted. Bivariate analyses were performed to identify possible associations between HPs usage with independent variables then a multiple logistic regression model was designed for later testing. We presented odds ratios with $95 \%$ confidence intervals (CI). All analysis was carried out using SPSS, version 17.

\section{RESULTS}

A total of 600 adults participated in this study (response rate was $60 \%$ ). Of these adults, $67.3 \%$ of were women and $32.7 \%$ were men; $34.7 \%$ were aged $35-49$ years with the mean age of $33.7(\mathrm{SD}=12)$ (range 18-85). Almost twothirds of $(64.5 \%)$ were in $\geq$ high school level, $54.7 \%$ were married, $79.2 \%$ had nuclear family, $50.3 \%$ were employee, $69.3 \%$ were residing in city centre and $49.7 \%$ were in high income level. Eighty-five responses (14.2\%) had any chronic disease and of these $38.8 \%$ were suffering from cardiovascular disease and hypertension. Other chronic conditions suffered from; diabetes were $27.0 \%$, chronic obstructive pulmoner diseases were $16.6 \%$, romatoid diseases were $14.1 \%$, thyroid dysfunctions were $9.4 \%$ and others (depression, hepatitis B, Family Mediterranean Fever) were 14.1\%. All responses with chronic conditions were using current medication. Almost two-thirds of the responses indicated their general health status as "good level".

First of all, we asked the question: What comes to your mind when called HPs? Responses to this question included herbs $(82.2 \%)$, herbal medicines/ weight-loss pill $(54.2 \%)$, herbal teas $(66.2 \%)$ and healthy life products (1.5\%). Overall HPs utilization was $55.7 \%$. We also 
investigated the health problems treated by respondents via HPs, a majority of participants (47.6\%) were expressed for intestinal illness. Other common health issues teated by HPs were losing weight (35.6\%), musculoskeletal conditions $(29.0 \%)$ and alopecia $(25.7 \%)$. When asked "how did you get a result after using HPs?", more than half of said that "partially recovered" and nearly one-third of expressed as "good for nothing". A minority reported suffer from damaged via HPs.

Table 2: Overall utilization and common health issues treated via HPs.

\begin{tabular}{|lll|}
\hline Utilization $(\mathbf{n = 6 0 0})$ & Number & $\%$ \\
\hline Using HPs & \multicolumn{2}{l|}{} \\
\hline Yes & 334 & 55.7 \\
\hline No & 266 & 44.3 \\
\hline Common health issues treated via & HPs $(\mathbf{n}=\mathbf{3 3 4})$ \\
\hline Intestinal illness & 159 & 47.6 \\
\hline Losing weight & 119 & 35.6 \\
\hline Musculoskeletal conditions & 97 & 29.0 \\
\hline Alopecia & 86 & 25.7 \\
\hline Chronic diseases & 53 & 15.9 \\
\hline Immunity support & 18 & 5.4 \\
\hline Anxiety & 8 & 2.4 \\
\hline Sexual problems & 2 & 0.6 \\
\hline Treatment results $(\mathbf{n}=334)$ & & \\
\hline Completely recovered & 40 & 12.0 \\
\hline Partially recovered & 185 & 55.4 \\
\hline Good for nothing & 90 & 26.9 \\
\hline Suffer damage & 19 & 5.7 \\
\hline
\end{tabular}

Adults responses to queries concerning their attitudes towards HPs demonstrate disharmony. Among adults $71.8 \%$ of reported that consuming high amounts of the HPs could be detirmental. Interestingly, a majority of (70.5\%) were looking optimistically using HPs and puul out of medication that prescribed by physician. In addition, a large number of respondents $(67.3 \%)$ thought that they gave up using it when heard one of damaged due to HPs. Nearly, two-third of thought some of the HPs might be killer.

However, more than half of thought HPs could change the effect of drugs when used in conjunction with it. Some respondents expressed HPs were harmless (40.3\%) and it's usage was easier than medicines $(40.2 \%)$. More than one-third of said that they would never use HPs for their child. Also, 29.0\% were believed that HPs were more effective than medicines and $25.0 \%$ were thought using HPs along with medicine due to illness. A minority of $(16.8 \%)$ expressed they should notify to doctor who regulate medication when using HPs for therapeutic purpose, $15.7 \%$ thought those who marketing HPs pay regard of public health. Only a small number of respondents $(9.0 \%)$ indicated that HPs advertisements were believable in the media.

Table 3 provides the results obtained from the HPs prevalence according to respondent's characteristics. As can be seen from the Table 3, there was no significant difference between age groups, marital status, educational level, occupation status, location of residence and income level for using HPs. Respondents using HPs were more often women, had large family, had any chronic condition, use medication currently and had "moderatebad" health perception $(\mathrm{p}<0.01)$.

Table 3: Respondent's attitudes towards to HPs.

\begin{tabular}{|c|c|c|c|c|}
\hline \multirow{2}{*}{ Attitudes $(n=600)$} & \multicolumn{2}{|l|}{ Yes } & \multicolumn{2}{|c|}{ No/undecided } \\
\hline & n & $\%$ & n & $\%$ \\
\hline Consumption of high amounts of the HPs could be detrimental & 431 & 71.8 & 169 & 28.2 \\
\hline Looking optimistically using HPs and pull out of medication that prescribed by physician & 423 & 70.5 & 177 & 29.5 \\
\hline Give up using it when heard one of damaged due to HPs & 404 & 67.3 & 196 & 32.6 \\
\hline Some of the HPs might be killer & 371 & 61.8 & 229 & 38.1 \\
\hline HPs could change the effect of drugs when used in conjunction with it & 343 & 57.2 & 257 & 42.8 \\
\hline It's harmless & 242 & 40.3 & 358 & 59.7 \\
\hline It's usage easier than medicines & 241 & 40.2 & 359 & 59.8 \\
\hline Never use HPs for their child & 223 & 37.2 & 377 & 62.8 \\
\hline It's more effective than medicines & 174 & 29.0 & 426 & 71.0 \\
\hline Using HPs along with medicine due to illness & 150 & 25.0 & 450 & 75.0 \\
\hline Should notify to doctor who regulate medication when use HPs for therapeutic purpose & 101 & 16.8 & 499 & 83.2 \\
\hline Those who marketing HPs pay regard for public health & 94 & 15.7 & 516 & 84.3 \\
\hline HPs advertisements believable in the media & 54 & 9.0 & 546 & 91.0 \\
\hline
\end{tabular}

It is apparent from this table that the odds of women to be in a category of "using herbal products" were 1.91 times higher than men. Similarly, the odds of those had large family were 2.03 times higher than who had nuclear 
family. One anticipated finding was that the odds of adults with chronic condition were 1.13 times higher than those without chronic condition. The odds of current medication for respondents said "yes" were 2.04 times higher than said "no".

Table 4: Using HPs according to respondent characteristics.

\begin{tabular}{|c|c|c|c|}
\hline \multirow{2}{*}{ Characteristics } & \multicolumn{2}{|c|}{ Using HPs } & \multirow{2}{*}{ p-value } \\
\hline & $\mathbf{n}$ & $\%$ & \\
\hline \multicolumn{4}{|l|}{ Age (years) } \\
\hline $18-24$ & 107 & 58.2 & \multirow{4}{*}{0.227} \\
\hline $25-34$ & 72 & 48.3 & \\
\hline $35-49$ & 121 & 58.2 & \\
\hline$\geq 50$ & 34 & 57.6 & \\
\hline \multicolumn{4}{|l|}{ Gender } \\
\hline Men & 94 & 48.0 & \multirow{2}{*}{0.008} \\
\hline Women & 240 & 59.4 & \\
\hline \multicolumn{4}{|l|}{ Marital status } \\
\hline Married & 174 & 53.0 & \multirow{2}{*}{0.156} \\
\hline Not-married & 160 & 58.8 & \\
\hline \multicolumn{4}{|c|}{ Educational level } \\
\hline$<$ High school & 129 & 60.6 & \multirow{2}{*}{0.073} \\
\hline$\geq$ High school & 205 & 53.0 & \\
\hline \multicolumn{4}{|l|}{ Family size } \\
\hline Large & 88 & 70.4 & \multirow{2}{*}{0.000} \\
\hline Nuclear & 246 & 51.8 & \\
\hline \multicolumn{4}{|l|}{ Occupation } \\
\hline Employee & 163 & 54.0 & \multirow{2}{*}{0.401} \\
\hline Unemployed & 171 & 57.4 & \\
\hline \multicolumn{4}{|c|}{ Location of residence } \\
\hline Centre & 222 & 53.4 & \multirow{3}{*}{0.193} \\
\hline District & 69 & 62.7 & \\
\hline Village & 43 & 58.1 & \\
\hline \multicolumn{4}{|l|}{ Income level } \\
\hline$\leq 500 \$$ & 179 & 59.3 & \multirow{2}{*}{0.074} \\
\hline$>500 \$$ & 155 & 52.0 & \\
\hline \multicolumn{4}{|c|}{ Medical condition } \\
\hline Yes & 62 & 72.9 & 0.001 \\
\hline No & 272 & 52.8 & \\
\hline \multicolumn{4}{|c|}{ Current medication use } \\
\hline Yes & 61 & 73.5 & \multirow{2}{*}{0.000} \\
\hline No & 273 & 52.8 & \\
\hline \multicolumn{4}{|c|}{ Current general health } \\
\hline Good & 185 & 50.1 & \multirow{2}{*}{0.001} \\
\hline Moderate-bad & 149 & 64.5 & \\
\hline Overall & 334 & 55.7 & \\
\hline
\end{tabular}

However, the odds of "moderate-bad" general health perception for using herbal products were 1.56 times higher than those with "good" health. Attitude -11 (I never use herbal products for my child) is also a strongest significant predictor with the odds ratio of 1.8 which indicates that respondents are more agree to not use herbal products for their children. Similarly, the more someone agrees with Attitude-7 (I think I should notify to doctor who regulate my medication when I use HPs for therapeutic purpose). The odds of ratio were 1.63 times higher than those with unagree.

Table 5: Predictors of respondent's HPs usage $(n=334)$.

\begin{tabular}{|lll|}
\hline Variables & Odds ratio & 95\% CL \\
\hline Demographic factors & & \\
\hline Gender, woman & 1.91 & $1.29-2.82$ \\
\hline Family type, large family & 2.03 & $1.27-3.24$ \\
\hline Chronic condition, yes & 1.13 & $0.15-8.44$ \\
\hline $\begin{array}{l}\text { Current medication use, } \\
\text { yes }\end{array}$ & 2.04 & $0.28-0.84$ \\
\hline $\begin{array}{l}\text { General health, moderate- } \\
\text { bad }\end{array}$ & 1.56 & $0.45-0.91$ \\
\hline Attitude toward HPs & & \\
\hline Attitude-3, yes & 0.59 & $0.39-0.87$ \\
\hline Attitude-4, yes & 0.56 & $0.32-0.98$ \\
\hline Attitude-7, yes & 1.63 & $1.06-2.51$ \\
\hline Attitude-11, yes & 1.80 & $1.20-2.68$ \\
\hline Attitude-12, yes & 0.57 & $0.36-0.92$ \\
\hline
\end{tabular}

\section{DISCUSSION}

This paper highlights the importance of herbal product usage and gives an account of knowledge and attitudes of Turkish adults. In Turkey, while some research has been carried out on patients, very little is known about HPs prevalence and attitudes in general population. In the present study, a high utilization of HPs among Turkish adult is found to be $55.7 \%$ which was similar to the previous Turkish study result $(55.4 \%) .{ }^{11}$ Conversely, a number of international studies have documented results on general population. Taken together, our study was also consistent with data obtained in other countries. Prevalence on use of HPs was reported as $33.9 \%$ in Malaysian adults; in Czech adults as $56.6 \%$; in American population as $57.3 \%$; in Arabian population was $77.6 \%$. $^{3,8,12,13}$

Most common health issues treated via HPs by respondents was found to be intestinal illness and losing weight. Our findings are similar to Czech and American population. ${ }^{3,12,14}$ A possible explanation for these results may be that HPs are seen a bridge to support healthy life in developed nations. In contrast, results from developing nations such as Brunei Darussalam and Jamaica presented that HPs was often taken for solving chronic problems such as hypertension, diabetes or endocrine. ${ }^{15,16}$

One interesting finding that, predominantly negative but sophisticated attitudes towards to HPs. Majority of the responses were looking optimistically using HPs than medication that prescribed by physician on the other hand a minority of thought that it was more effective than medicines. These findings reflected that responses had 
dizzy information and support the idea of lack of knowledge about HPs. 5,7

In present study, the second major finding was that factors which were influence of HPs including gender, family type, chronic condition, medication use and general health perception. Our study is consistent with various studies that women were more likely to be users than men. $3,8,17,18$ However, the multivariate analysis showed that the odd of women being a user about 1.9 times higher than men. Gender differences may partly explained by disparity in health needs and social factors such as beliefs and attitudes.

It is somewhat surprising that one study was noted in family size. The odd of having large family being a user was 2.03 times higher than of have a nuclear family. In large family, members may encourage themselves using for HPs. Conversely it was indicated more likely who live in nuclear family. ${ }^{19}$

Not surprisingly, use of HPs showed significantly higher differences by chronic condition and current medication use. Also chronic condition and current medication use was a significant predictor of HPs use. The odds of having chronic condition was 1.13 and using current medication was 2.04 times higher than said "no". Similarly, previous studies have shown that health problem and current medication use had an influence on HPs. ${ }^{5,8,18}$ Chronic disease are long term disease and their management require being patient for medication and lifestyle changes otherwise picture of disease become heavier. It seems possible that some people with chronic condition use HPs along with medicine due to apate the complaints.

Another important finding is that general health status which is in uncorrespondence with another study. ${ }^{19}$ HPs use was significantly higher in adults who had "moderatebad" health perception. The odd was 1.56 times higher than those had "good" perception. Some physiological and psychological factors may lead to low health perception and people may be use HPs for the purpose of promoting their health status due to thinking their natural origin.

However, we found a satisfactory finding those responses had mindful attitudes about their children and their doctor's consideration for using HPs.

\section{CONCLUSION}

The present study confirms previous findings and provides additional evidence that using HPs among Turkish adults is still prevalent. However, the most obvious finding to emerge from this study is that semipositive attitudes towards to HPs. So it needs to be emphasized that more information on HPs would help Turkish adults to establish a greater degree of accuracy on this matter. Ensuring appropriate information systems, services and support should be a priority within the framework of the Ministry of Health-primary health care systems to prevent miss usage and haphazard by adults.

Funding: No funding sources

Conflict of interest: None declared

Ethical approval: The study was approved by the Institutional Ethics Committee

\section{REFERENCES}

1. World Health Organization 2004. WHO guidelines on safety monitoring of herbal medicines in pharmaco vigilance systems. Available at: http://apps.

who.int/medicinedocs/documents/s7148e/s7148e.pdf. Accessed 10 July 2016.

2. UNICEF/UNDP/World Bank/World Health Organization 2005. Special Programme for Research and Training in Tropical Diseases: Operational guidance: Information needed to support clinical trials of herbal products. Available at: http://www.who.int/tdr/publications/documents/opera tional-guidance-eng.pdf. Accessed 10 July 2016.

3. Knotek K, Verner V, Chaloupkova P, Kokoska L. Prevalence and use of herbal products in the Czech Republic: over-the-counter survey among adult pharmacies clients. Complement. Ther Med. 2012;20:199-206.

4. World Health Organization 2002. WHO traditional medicine strategy 2002-2005. Available from: http://www.wpro.who.int/health_technology/ book_ who_traditional_medicine_strategy_2002_2005.pdf. Accessed 10 July 2016.

5. Marinac JS, Buchinger CL, Godfrey LA, Wooten JM, Sun C, Willsie SK. Herbal products and dietary supplements: A survey of use, attitudes, and knowledge among older adults. JAOA. 2007;107(1):13-23.

6. Gonzalez-Stuart A. Herbal products use by older adults. Maturitas. 2011;68:52-5.

7. Sekhri K, Bhanwra S, Nandha R. Herbal products: a survey of students' perception and knowledge about their medicinal use. Int $\mathrm{J}$ Basic Clin Pharmacol. 2013;2(1):71-6.

8. Aziz Z, Tey NP. Herbal medicines: Prevalence and predictors of use among Malaysian adults. Complement Ther Med. 2009; 17: 44-50.

9. Koc Z, Avc1 IA, Saglam Z. The use of complementary and alternative medicine by older patients that have chronic diseases. Health Med. 2012;6:413-22.

10. Algier LA, Hanoglu Z, Ozden G, Kara F. The use of complementary and alternative (non-conventional) medicine in cancer patients in Turkey. Eur $\mathrm{J}$ Oncol Nurs. 2005;9:138-46.

11. Aydın S, Bozkaya AO, Mazıcıŏlu M, Gemalmaz A, Özçakır A, Öztürk A. What Influences Herbal Medicine Use? Prevalence and Related Factors. Turk J Med Sci. 2008;38(5):455-63. 
12. Kennedy J. Herb and supplement use in the US adult population. Clin Ther. 2005;27(11):1847-58.

13. AlBraik FA, Rutter PM, Brown D. A cross-sectional survey of herbal remedy taking by United Arab Emirate (UAE) citizens in Abu Dhabi. Pharmacoepidemiol Drug Saf. 2008;17(7):725-32.

14. Gardiner P, Graham R, Legedza AT, Ahn AC, Eisenberg DM, Phillips RS. Factors associated with herbal therapy use by adults in the United States. Altern Ther Health Med. 2007;13(2):22-9.

15. Chong VH, Rajendran N, Wint Z. Prevalence and predictive factors for complementary and alternative medicine use in Brunei Darussalam. Singapore Med J. 2008;49(12):1012.

16. Delgoda R, Younger N, Barrett C, Braithwaite J, Davis D. The prevalence of herbs use in conjunction with conventional medicines in Jamaica. Complement Ther Med. 2010;18(1):13-20.
17. Lim MK, Sadarangani P, Chan HL, Heng JY. Complementary and alternative medicine use in multiracial Singapore. Complement. Ther Med. 2005;13(1):16-24.

18. Gunther S, Patterson RE, Kristal AR, Stratton KL, White E. Demographic and health-related correlates of herbal and specialty supplement use. J Am Diet Assoc. 2004;104(1):27-34.

19. Nur N. Knowledge and behaviors related to herbal remedies: a cross-sectional epidemiological study in adults in Middle Anatolia, Turkey. Health Soc Care Community. 2010;18(4):389-95.

Cite this article as: Yilmazel G, Naçar M. Herbal products: utilization, knowledge and attitudes of Turkish adults. Int $\mathrm{J}$ Basic Clin Pharmacol 2016;5:2426-31. 